Claude Eric Klopfenstein MD, Alain Forster MD, Elisabeth Van Gessel MD

\section{Anesthetic assessment in an outpatient consulta- tion clinic reduces preoperative anxiety}

Purpose: Preoperative anxiety in relation to anesthesia remains for many patients a major subject of concern. The aim of the present study was to compare the level of preoperative anxiety in patients assessed in an outpatient consultation clinic with the anxiety level of those having been assessed by the anesthesiologist after entering the hospital.

Method: We studied two groups of 20 patients who underwent elective transurethral prostate or bladder resection: group A having the anesthetic assessment between one-two weeks before hospitalisation, group B having this assessment the evening before surgery, after entering the hospital. Two different methods to assess anxiety were used: the Multiple-Affect-Adjective-Check-List (MAACL) and the visual analogue scale of anxiety (VAS).

Results: Both anxiety provided scores, assessed by two different methods, were lower in group $A$, than in group $\mathrm{B}(P<0.01)$.

Conclusion: The results of this study confirm that an anesthetic assessment in an outpatient consultation clinic reduces preoperative anxiety, when compared with an assessment on the evening before surgery.

Objectif : L'anxiété préopératoire reste aujourd'hui encore un phénomène mal résolu pour le patient. Le but de la présente étude est de comparer l'impact de deux types de visites préanesthésiques sur l'anxiété préopératoire : l'une, dans une clinique de consultation externe, l'autre, le jour avant l'opération alors que le patient est hospitalisé. Méthode : Deux groupes de 20 patients, dont l'intervention chirurgicale urologique endoscopique avait été planifiée, ont été étudiés. Dans le groupe A, l'évaluation anesthésique a été réalisée une à deux semaines avant l'opération dans une clinique de consultation externe; dans le groupe B, il s'agissait de la visite préanesthésique la veille de l'opération et le patient était déjà hospitalisé. Nous avons utilisé 2 méthodes pour mesurer l'anxiété : un test verbal d'anxiété, selon Zuckermann, et une échelle visuelle analogique.

Résultats : Les patients du groupe $A$ ont présenté un score d'anxiété préopératoire significativement plus bas $(P$ $<0,0$ I) que ceux du groupe $B$, et cela selon les 2 méthodes de mesures de l'anxiété utilisées dans notre étude. Conclusion : Les résultats de cette étude confirment qu'une consultation anesthésique externe réalisée une à deux semaines avant l'opération réduit significativement l'anxiété préopératoire du patient, comparée à une visite préanesthésique la veille de l'opération.

From the Department of Anaesthesiology, Clinical Pharmacology and Surgical Intensive Care, University Hospitals, Geneva, Switzerland. Address correspondence to: Claude Eric Klopfenstein MD, Department of Anaesthesiology, Clinical Pharmacology and Surgical Intensive Care, University Hospitals, CH 1211 Geneva 14, Switzerland. Phone: 41-22-38-27-403; Fax: 41-22-38-27-511;

E-mail: Claude-Eric.Klopfenstein@hcuge.ch Accepted for publication March 2, 2000. 
$\mathrm{P}$ REOPERATIVE anxiety in relation to anesthesia remains for many patients a major subject of concern. ${ }^{1-5}$ Anxiety is described as an unpleasant state of uneasiness or tension which may be associated with abnormal hemodynamics as a consequence of sympathetic, parasympathetic and endocrine stimulation. It begins as soon as the surgical procedure is planned and increases to maximal intensity at the moment of entering the hospital. ${ }^{6}$

One of the aims of preanesthetic assessment is to reduce fear and anxiety, as demonstrated in a previous study. ${ }^{7}$ A preanesthetic visit during hospitalisation often encounters major difficulties, such as absence of a consulting facility and privacy, or unavailability of the patient because of other preoperative consultations. Moreover, it is accepted that reassurance of the patient just before surgery is often insufficient to reduce anxiety. ${ }^{8-9}$

Preanesthetic assessment in an outpatient consultation clinic has been developed recently. ${ }^{8-11}$ Besides financial advantages and increased performances in the operating room activity, ambulatory anesthetic consultations are appreciated by the patients. ${ }^{9}$ Nevertheless, only a few contradictory reports have analysed the benefits of such a consultation on the anxiety level of the patient before surgery. ${ }^{12-13}$

The aim of the present study was to compare the level of preoperative anxiety in patients having a preanesthetic assessment after arriving at hospital, on the evening before surgery, with those assessed in an outpatient consultation clinic. Our hypothesis is that preoperative anxiety would decrease when patients are assessed in an outpatient consultation clinic.

Subjects and method

After obtaining approval from the Local Ethics Committee, and informed consent, 40 consecutive adults ASA score I to III, $<65 \mathrm{yr}$, scheduled for an urological procedure, were selected for the study and randomly attributed to two groups according to the type of preanesthetic assessment (Table I). None of the patients had previous anesthetic experience. In group A, patients had a preanesthetic consultation in an outpatient clinic one-two weeks before hospitalisation, performed by the same consultant not involved in the study. Just after entering hospital, their anxiety state was assessed by the first author. This was followed by a short preanesthetic visit to confirm state of health and consent of the patient, performed by the anesthetic resident in charge of the inhospital urological patients. In group B, the patients had no preanesthetic consultation before hospitalisation, were assessed by the resident in charge just after entering the hospital, on the day before surgery; this was followed by the assessment of the anxiety state performed by the first author. Neither the consultant anesthesiologist, nor the resident in charge, nor the first author were aware of the group to which the patients had been attributed. Two different methods were used to assess the anxiety state of the patient: a) the Multiple-Affect-AdjectiveCheck-List (MAACL) and a visual analogue scale of anxiety (VAS). The MAACL is a verbal score of anxiety, first described by Zuckermann in $1960^{14}$ and used in several studies. ${ }^{15-17}$ It consists of 21 adjectives presented in random order (Appendix). Patients are asked to tick off all those words which best describe their feelings at the moment of the interview. One point was scored for each of the 11 «anxiety present» adjectives selected $(+)$ and also for each of the 10 «anxiety absent» not selected (-). The possible range of scores was therefore 0 to 21 , with higher scores indicating greater levels of anxiety. A VAS to assess preoperative anxiety was used in previous studies. ${ }^{17-18}$ On a graduated scale rated from 0 (no anxiety at all) to 10 (very high anxiety), the patient had to indicate the level of his anxiety at the moment of the interview.

Data are expressed as mean \pm SD and median and range, statistical differences between the two groups being detected with unpaired t Test, Chi square and Mann-Whitney two sample tests. The Pearson correlation coefficient was calculated to analyse the relationship between the two methods of anxiety assessment. A $P<0.05$ was considered as significant.

\section{Results}

Both groups were comparable when considering age, weight, height, sex, ASA physical status, the type of surgery and of anesthesia (Table II).

The anxiety scores according to the MultipleAffect-Adjective-Check-List (MAACL) are shown on Figure 1 . The median anxiety score in group A is $3(0-$ 9 ) and in group B 6.5 (2-12); this score is significant-

TABLE I Sequences of the different assessments

\begin{tabular}{|c|c|c|c|c|}
\hline \multirow[b]{2}{*}{ group $A(n=20)$} & \multirow{2}{*}{$\begin{array}{l}\text { 1-2 weeks before hospitalisation } \\
\text { ambulatory preanesthetic consultation }\end{array}$} & \multicolumn{3}{|c|}{ hospitalisation: day before surgery } \\
\hline & & $\varnothing$ & anxiety assessment & $\begin{array}{l}\text { inhospital } \\
\text { preanesthetic visit }\end{array}$ \\
\hline group $B(n=20)$ & $\varnothing$ & $\begin{array}{l}\text { inhospital preanesth } \\
\text { consultation }\end{array}$ & anxiety assessment & $\varnothing$ \\
\hline
\end{tabular}


APPENDIX The Multiple Affect Adjective Check List (MAACL) "please tick off all those words which describe your feeling at the moment»

\begin{tabular}{llllll}
\hline upset & $(+)$ & cheerful & $(-)$ & afraid & $(+)$ \\
thoughtful & $(-)$ & frightened & $(+)$ & loving & $(-)$ \\
happy & $(-)$ & calm & $(-)$ & panicky & $(+)$ \\
terrified & $(+)$ & shaky & $(+)$ & pleasant & $(-)$ \\
contented & $(-)$ & fearful & $(+)$ & worrying & $(+)$ \\
nervous & $(+)$ & steady & $(-)$ & secure & $(-)$ \\
tense & $(+)$ & desperate & $(+)$ & joyful & $(-)$ \\
\hline
\end{tabular}

$(+)$ : anxiety present

$(-)$ : anxiety absent

TABLE II Epidemiology of the selected patients

\begin{tabular}{llll}
\hline & group $A$ & group $B$ & \\
\hline age yr (mean \pm SD) & $65.3 \pm 12.1$ & $58.6 \pm 18.5$ & NS \\
weight kg (mean \pm SD) & $73.8 \pm 2.2$ & $71.6 \pm 9.6$ & NS \\
$\begin{array}{l}\text { height cm (mean } \pm \text { SD) } \\
\text { sex: female/male }\end{array}$ & $169.2 \pm 9.3$ & $169.0 \pm 8.8$ & NS \\
$\begin{array}{l}\text { ASA physical risk scoring: } \\
\text { I/II/III }\end{array}$ & $4 / 16$ & $1 / 19$ & NS \\
$\begin{array}{l}\text { surgical procedure } \\
\begin{array}{l}\text { (TURP/bladder resection) } \\
\text { type of anesthesia } \\
\text { (general } v \text { regional) }\end{array}\end{array}$ & $13 / 12 / 1$ & $11 / 7 / 2$ & NS \\
\hline
\end{tabular}

ly lower in group A when compared to group $\mathrm{B}(P=$ $0.0053)$. The anxiety scores according to the Visual Analog Scale (VAS) are shown in Figure 2. The median anxiety score is $3(0-5)$ in group A and $5(2-8)$ in group $\mathrm{B}$; this score is significantly lower in group A when compared with group $\mathrm{B}(P=0.0038)$. The Pearson correlation coefficient between the two methods of anxiety assessment is significant $(\mathrm{r}=0.641)$.

\section{Discussion}

The results of this study demonstrate that patients who undergo an ambulatory preanesthetic consult between one-two weeks before hospitalisation have less preoperative anxiety, than patients who are assessed by the anesthesiologist just after entering the hospital. In addition to the well known advantages of an anesthesia outpatient consultation clinic, such as lowering the hospital costs and improving operating room efficiency, the results of this study confirm the effectiveness of an anesthesia outpatient setting in reducing preoperative anxiety. ${ }^{8-9}$ This is the first report which was specifically designed to determine the impact of an anesthesia outpatient consultation clinic on preoperative anxiety.

The results of the present study are relevant and the selected patients consist of a homogenous population.

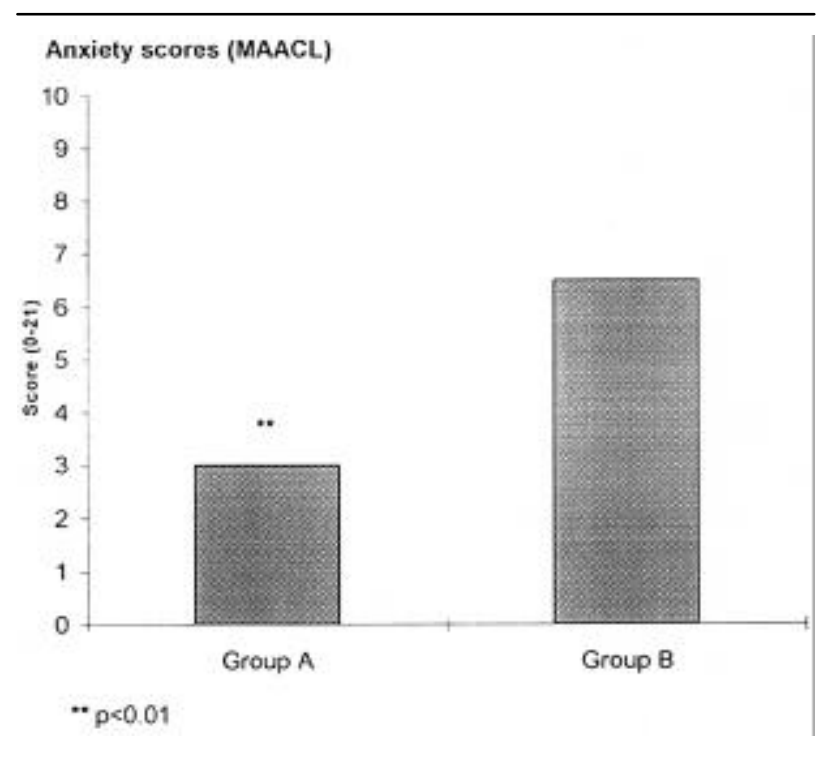

FIGURE 1 Anxiety scores in both groups using the MultipleAffect-Adjective-Check-List (MAACL); the scores are expressed as median and range; group A: ambulatory preanesthetic consultation, group B: no ambulatory preanesthetic consultation.

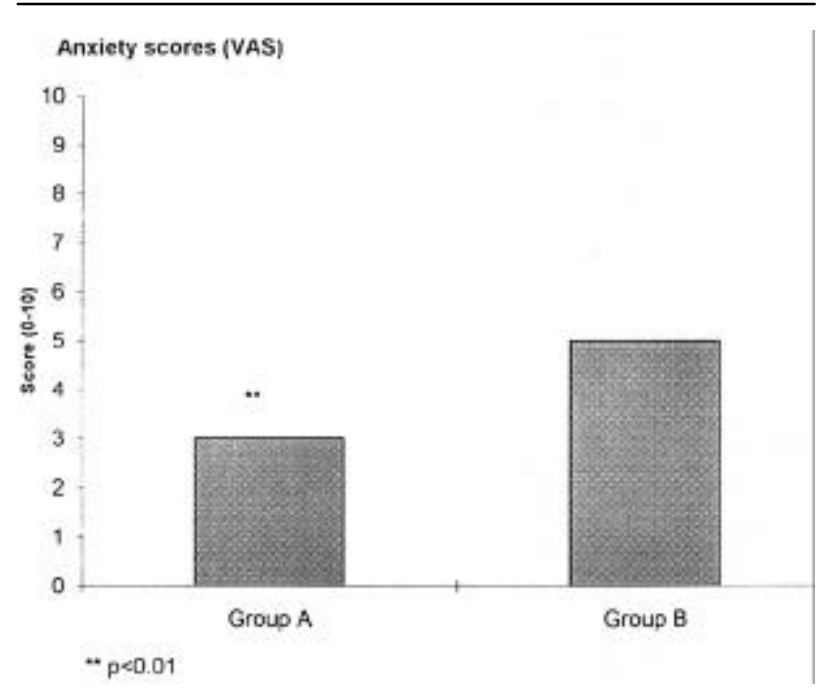

FIGURE 2 Anxiety scores in both groups using the visual analogue scale (VAS), the scores are expressed as median and range; group A: ambulatory preanesthetic consultation, group B: no ambulatory preanesthetic consultation.

They were all scheduled for endoscopic urological surgery, which is recognised as a low invasive procedure. There is an effect of the type of surgery on preoperative anxiety level, invasive or mutilating surgery being more anxyogenic than non invasive surgery. ${ }^{19-20}$ 
Moreover, they had no previous anesthetic experience; as described, it is assumed that patients who had previous anesthetic experience would be less anxious than patients awaiting for their first anesthesia. ${ }^{19-20}$

The results of the present study may suffer from bias. The assessment of anxiety was performed on the evening before surgery, just after entering the hospital. As described in a previous study, the evening anxiety scores are not correlated with those on the morning just before surgery, which represent the highest level of anxiety. ${ }^{2}$ Finally, the anesthesiologist in charge of the consultation clinic was a consultant, whereas a resident performed the assessment on hospital admission. A more experienced staff anesthesiologist is probably more able and willing to work as a "contact person", providing the patient with emotional support, which is more effective in reducing anxiety than cognitive and informative support alone. ${ }^{2} 2$

Anxiety is a complex process, resulting in an unpleasant state of uneasiness or tension. To assess it, the most commonly used instrument is the Spielberger's StateTrait Anxiety Inventory (STAI). ${ }^{2}$ The STAI questionnaire is a global test and measures trait and state of anxiety. Nevertheless, this test is time consuming, difficult to complete, and often requires the help of a psychologist. For these reasons, we chose two alternatives: the Multiple-Affect-Adjective-Check-List and the Visual Analogue Scale. Both are easy to complete in a bed-side situation and are reliable. Finally, in our study, the VAS scores were found to be correlated with the MAACL scores, as previously described. ${ }^{17}$

It is difficult to compare the results of the present study with previous studies on preoperative anxiety because of variations in the methods used to measure anxiety, the differences in the populations studied and the design of the studies. Egbert and co-workers concluded that the anesthetic visit was more effective than a medication in reducing preoperative anxiety; nevertheless they studied anxiety in inpatients prior to elective surgery, independently of the type of preanesthetic assessment. ${ }^{7}$ Leigh and co-workers, using the STAI to quantify the effect of the anesthetic visit on anxiety, found a reduction in anxiety score if their patients were assessed preoperatively by the anesthesiologist. ${ }^{12}$ On the contrary, Twersky, using the same method to assess anxiety, stated that patients did not benefit from reducing preoperative anxiety by visiting the anesthesiologist before the day of surgery. ${ }^{13}$ Mackenzie evaluated preoperative anxiety in patients scheduled for different types of surgery under general anesthesia, using the MAACL and the VAS. ${ }^{20}$ In these two reports, only patients scheduled for outpatient surgery were studied, which could be considered a much less stressful environment than is inpatient. ${ }^{24}$
An anesthetic assessment in an outpatient consultation clinic allows the patient to be assessed in a quiet and relaxed atmosphere. In this way, more detailed information can be presented in an easily understood manner and in a location away from the threatening environment of a large hospital ward, thus allowing a higher patient satisfaction, as has been reported previously. ${ }^{25}$

In conclusion, under the conditions of the present study, anesthetic assessment in an outpatient consultation clinic reduced preoperative anxiety, compared with traditional assessment after the patient has entered the hospital. Moreover, the two methods used to assessed anxiety are alternatives to the Spielberger's State-Trait Anxiety Inventory, which is considered the gold standard. The results of this study support the concept that preoperative anxiety can be assessed using VAS alone.

\section{References}

1 Ramsay MAE. A survey of pre-operative fear. Anaesthesia 1972; 27: 396-402.

2 Norris W, Baird WLM. Pre-operative anxiety - a study of the incidence and aetiology. Br J Anaesth 1967; 39: 503-9.

3 Johnson M. Anxiety in surgical patients. Psychol Med 1980; 10: 145-52.

4 Badner NH, Nielson WR, Munk S, Kwiatkowska C, Gelb $A W$. Preoperatove anxiety: detection and contributing factors, Can J Anaesth 1990; 37: 444-7.

5 Fell D, Derbyshire DR, Maile CJD, et al. Measurement of plasma catecholamine concentrations. An assessment of anxiety. Br J Anaesth 1985; 57: 770-4.

6 McCleane GJ, Cooper $R$. The nature of pro-operative anxiety. Anaesthesia 1990, 45: 153-5.

7 Egbert LD, Battit GE, Turndorf H, Beecher HK. The value of the preoperative visit by an anesthetist. A study of doctor-patient rapport. JAMA 1963; 185: 553-5.

8 Finegan $B A$. Preadmission and outpatient consultation clinics (Editorial). Can J Anaesth 1992; 39:1009-11.

9 Conway JB, Goldberg J, Chung F. Preadmission anaesthesia consultation clinic. Can J Anaesth 1992: 39: $1051-7$.

10 Fischer SP. Development and effectiveness of an anesthesia peroperative evaluation clinic in a teaching hospital. Anesthesiology 1996; 85: 196-206.

11 Pollard JB, Zboray AL, Mazze RI. Economic benefits attributed to opening a preoperative evaluation clinic for outpatients. Anesth Analg 1996; 83: 407-10.

12 Leight JM, Walker J, Janaganathan P. Effect of preoperative anaesthetic visit an anxiety. BMJ 1977; 2: 987-9.

13 Twersky RS, Lebovits AH, Lewis M, Frank D. Early anesthesia evaluation of the ambulatory surgical patient: does it really help? J Clin Anesth 1992; 4: 204-7. 
14 Zuckerman $M$. The development of an affect adjective check list for the measurement of anxiety. J Consult Psychol 1960; 24: 457-62.

15 Herron EW, Bernstein L, Rosen H. Psychometric analysis of the multiple affect adjective check list: MAACLtoday. J Clin Psychol 1965; 24: 448-50.

16 Wassenaar W, Lancee WJ, Galloon S, Gale GD. The measurement of anxiety in the pre-surgical patient. Br J Anaesth 1977; 49: 605-8.

17 Hicks JA, Jenkins JG. The measurement of preoperative anxiety. J Royal Soc Med 1988; 81: 517-9.

18 Vogelsang J. The visual analog scale: an accurate and sensitive method for self-reporting preoperative anxiety. J Post Anesth Nursing 1988; 3: 235-9.

19 Domar AD, Everett LL, Keller MG. Preoperative anxiety: is it a predictable entity? Anesth Analg 1989; 69: 763-7.

20 Mackenzie JW. Daycase anaesthesia and anxiety. A study of anxiety profiles amongst patients attending a Day Bed Unit. Anaesthesia 1989; 44: 437-40.

21 Panda N, Bajaj A, Pershad D, Yaddanapudi LN, Chari $P$. Pre-operative anxiety. Effect of early or late position on the operating list. Anaesthesia 1996; 51: 344-6.

22 Elsass P, Duedahl H, Friis B, Møller I, Sørenson MB. The psychological effects of having a contact-person from the anesthetic staff. Acta Anaesthesiol Scand 1987; 31: 584-6.

23 Spielberger CD, Gorsuch RL, Lushene RE, Vagg PR, Jacobs GA. Manual for the State-Trait Anxiety Inventory. Palo Alto, CA: Consulting Psychologists Press, 1983.

24 Aranello R, Cruise C, Chung F. Timing of the anesthetist's preoperative outpatient interview. Analg Anesth 1989; 68: 645-8.

25 Murchison D. Preoperative outpatient consultation in private anaesthesia practice. NZ Med J 1991; 104 : 429-31. 